with a blower mister, because other mechanisms like crossclamping or cannulation of the ascending aorta bear a stroke risk of more than $8 \%$ in octogenarians ${ }^{3}$ and may have been the cause for emboli. However, we cannot rule out that air provided by the blower mister device entered the aorta through a leak between the proximal seal and the aortic wall and caused the emboli. The possibility of such a mechanism was proven in an animal experiment. This should be sufficient reason to strongly discourage the simultaneous use of the HEARTSTRING device in combination with a blower mister.

\section{References}

1. Guidant Corporation. HEARTSTRING Proximal Seal System. Instructions for use. Santa Clara, Calif. 2002.

2. Nollert G, Nagashima M, Bucerius J, et al. Oxygenation strategy and neurological damage after deep hypothermic circulatory arrest. Part I. Gaseous emboli. J Thorac Cardiovasc Surg. 1999;117:116671.

3. Roach GW, Kanchuger M, Mangano CM, et al. Adverse cerebral outcomes after coronary bypass surgery. N Engl J Med. 1996;335:185763.

\title{
Life-threatening anaphylactic shock caused by porcine heparin intravenous infusion during mitral valve repair
}

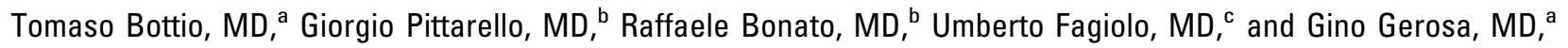
Padua, Italy

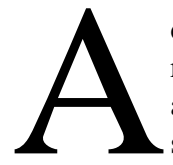

dverse skin reactions to low-molecular-weight heparin and systemic allergic reactions coupled with heparin-induced antibody reactions have been described. ${ }^{1-3}$ In this report we describe a case of cardiogenic anaphylactic shock caused by porcine gut heparin infusion in the cardiac surgery theater before starting cardiopulmonary bypass $(\mathrm{CPB})$ in a young man with degenerative mitral valve incompetence.

\section{Clinical Summary}

A 36-year-old man was referred to the Cardiovascular Institute of Padua University for mitral valve repair of valve incompetence caused by a floppy valve. He had a history for asthma treated with $\beta$-stimulants and a documented Acarus species allergy. He had mitral valve incompetence for about 6 years, which more recently progressed to New York Heart Association class II. Physical examination revealed significant systolic murmur (5/6 grade). Electrocardiography disclosed normal sinus rhythm (97 beats/ min), mild left ventricular hypertrophy, and an enlarged atrial component. The hematologic and biochemical values were within normal range. Chest radiography showed an increased cardiothoracic ratio. Two-dimensional echocardiography showed severe

\footnotetext{
From the Departments of Cardiovascular Surgery, ${ }^{\mathrm{a}}$ Anesthesiology, ${ }^{\mathrm{b}}$ and Allergology, ${ }^{\mathrm{c}}$ University of Padua, Padua, Italy.

Received for publication May 5, 2003; accepted for publication May 12, 2003.

Address for reprints: Tomaso Bottio, MD, Institute of Cardiovascular Surgery, Via Giustiniani, 2, 35128 Padova, Italy (E-mail: tomaso.bottio@unipd.it).

J Thorac Cardiovasc Surg 2003;126:1194-5

Copyright (C) 2003 by The American Association for Thoracic Surgery $0022-5223 / 2003 \$ 30.00+0$

doi:10.1016/S0022-5223(03)00813-4
}

mitral regurgitation and left atrial and ventricular dilatation with a normal ejection fraction. These data were confirmed by cardiac angiography with hemodynamic study. The spirometry analysis showed mild airways obstruction with reduced tidal volume.

After providing written informed consent, the patient received premedication consisting of $2 \mathrm{mg}$ of oral lorazepam administered 1 hour before the start of anesthesia. The patient was prepared by

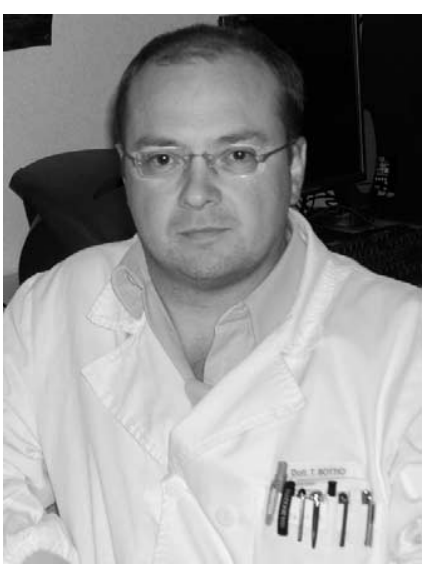

Dr Bottio introduction of an intravenous catheter in the right arm for balanced salt solution infusion and an arterial catheter with local anesthesia in the left radial artery for continuous blood pressure monitoring.

Monitoring also included electrocardiographic leads II and $\mathrm{V}_{5}$ with automated ST-segment analysis and trending, pulse oximetry, and capnography. After a 5-minute preoxygenation period, general anesthesia was induced with thiopental $(2.5 \mathrm{mg} / \mathrm{kg})$, followed by fentanyl $(5 \mu \mathrm{g} / \mathrm{kg})$ and vecuronium $(0.1 \mathrm{mg} / \mathrm{kg})$. After loss of consciousness, mask ventilation was maintained with $100 \%$ oxygen, and 2 minutes later, an endotracheal tube was introduced. Mechanical ventilation with a mixture of oxygen-air $(60 \%)$ was adjusted to maintain end-tidal carbon dioxide between 30 and 35 $\mathrm{mm} \mathrm{Hg}$, with an airway peak pressure of less than $25 \mathrm{~mm} \mathrm{Hg}$ and a normal capnography curve. Maintenance of anesthesia was achieved with fentanyl up to $20 \mu \mathrm{g} / \mathrm{kg}$ before sternotomy and with a continuous infusion of propofol $\left(3 \mathrm{mg} \cdot \mathrm{kg}^{-1} \cdot \mathrm{h}^{-1}\right)$ and cisatracurium $\left(1.5 \mu \mathrm{g} \cdot \mathrm{kg}^{-1} \cdot \mathrm{min}^{-1}\right)$. Intravenous antibiotic prophylaxis (cephazolin, $30 \mathrm{mg} / \mathrm{kg}$ ) was given. After induction of anes- 
thesia, an internal jugular vein was cannulated for drug infusion and central venous pressure monitoring.

Before administration of intravenous heparin, no adverse events with hemodynamic or respiratory alterations were observed, and there was an absence of skin reactions of every type, even after antibiotic therapy.

Before the start of CPB, a complete dose of porcine gut heparin (300 IU/ $/ \mathrm{kg}^{-1}$; Epsoclar; Biologici Italia Laboratories S.r.l.) was administered. Immediately thereafter, the blood pressure decreased from $130 / 60$ to $30 / 10 \mathrm{~mm} \mathrm{Hg}$, despite infusion of metaraminol, epinephrine, norepinephrine, methylprednisolone, and salbutamol. An airway stoppage without the possibility of mechanical ventilation occurred despite tracheobronchial puffs of epinephrine and ipratropium, and 2 minutes later, the heart had fibrillated. In emergency status the blood flow was restored during CPB. At tracheobronchoscopy, the mucus membrane of the airways seemed edematous, and the lumen seemed virtual. The patient was operated on with a continuous infusion of epinephrine to maintain an adequate mean blood pressure; moderate hypothermia; cardioplegic arrest with cold blood intermittent, antegrade, and retrograde cardioplegia; and additional topical cooling with ice slush. The native mitral valve was repaired by means of posterior leaflet rectangular resection reinforced by a Carpentier ring $(30 \mathrm{~mm})$ implanted with single stitches. The patient was weaned from CPB smoothly after restoring an acceptable ventilation with intravenous infusion of methylprednisolone ( $1 \mathrm{mg} / \mathrm{kg}$ per dose), salbutamol $\left(0.5 \mu \mathrm{g} \cdot \mathrm{kg}^{-1} \cdot \mathrm{min}^{-1}\right)$, and dopamine $\left(4 \mu \mathrm{g} \cdot \mathrm{kg}^{-1} \cdot \mathrm{min}^{-1}\right)$.

The patient was extubated in the intensive care unit 8 hours later, and he was discharged on the third postoperative day on a regimen of oral anticoagulation (warfarin) without antiplatelet therapy. The patient was discharged home free of cardiac and breathing symptoms, intravenous salbutamol was translated to puff, and methylprednisolone was discontinued. Thrombocytopenia was never observed in this patient.

Oral anticoagulation was discontinued 3 months after the operation, as is our protocol with mitral valve repair. Two months later, after all drug intake had been interrupted (oral anticoagulants, angiotensin-converting enzyme inhibitors), the patient underwent skin prick testing for allergic sensitization measurement. The results were compared with those of 9 patients followed for sensitization to common environmental allergens. Skin testing was performed by the same individual using porcine gut heparin at growing dilution. Skin reactivity was observed only in our patient, and he had positive results for even the highest dilution.

\section{Discussion}

We have reported a life-threatening case of unexpected and irreversible cardiac shock, despite immediate drug administration, after full heparinization and before commencing CPB.

Anaphylactic reactions were already noted and reported in the clinical setting in the early phase of heparin use. ${ }^{4}$ Today, because the purified heparin was introduced in clinical use, cases of porcine heparin anaphylactic reaction have been observed only rarely.,5

In the English-language literature a fatal case caused by heparin reaction was described by Ansell and colleagues ${ }^{6}$ in 1986. During a cardiac operation, Harada and coworkers ${ }^{3}$ reported on a 7-yearold girl with reactions similar to those of our patient caused by heparinized saline solution being used to flush the radial artery. In that case the pressure decreased from $130 / 90$ to $60 / 0 \mathrm{~mm} \mathrm{Hg}$.

The peculiarity of what we are reporting is the systemic reaction with circulatory collapse and airway blockage despite the massive drug attack with catecholamine, steroids, and $\beta$-stimulants. The only choice we had to save the patient's life was to start $\mathrm{CPB}$ in overflow $(130 \%)$, reducing the body temperature $\left(28^{\circ} \mathrm{C}\right)$ to ensure a mean arterial pressure of at least $50 \mathrm{~mm} \mathrm{Hg}$ with $100 \%$ oxygen fraction because of the contemporaneous airway ventilation arrest. We decided at this point, with an activated clotting time of 420 seconds, to operate on the patient. The mitral valve was repaired, and the patient was carefully weaned from CPB supported with a continuous infusion of catecholamine and steroid coupled with salbutamol for airway ventilation.

\section{References}

1. Wutschert R, Piletta P, Bounameaux H. Adverse skin reactions to low molecular weight heparins: frequency, management and prevention. Drug Saf. 1999;20:515-25.

2. Folwaczny EK, Sturmer KM. Atypical heparin-induced thrombocytopenia (HIT) heparin allergy with thrombocytosis. Chirurgie. 1999;70: 588-93.

3. Harada A, Tatsuno K, Kikuchi T, Takahashi Y, Sai S, Murakami Y, et al. Use of bovine lung heparin to obviate anaphylactic shock caused by porcine gut heparin. Ann Thorac Surg. 1990;49:826-7.

4. Dux S, Pitlik S, Perry G, Rosenfeld JB. Hypersensitivity reaction to chlorbutol-preserved heparin. Lancet. 1981;1(8212):149.

5. Rosenzweig P, Gary NE, Gocke DJ, Saidi P, Felton SM, Eisinger RP. Heparin allergy accompanying acute renal failure. Artif Organs. 1979; 3:78-9.

6. Ansell JE, Clark WP, Compton CC. Fatal reactions associated with intravenous heparin. Drug Intell Clin Pharm. 1986;20:74-5. 